\title{
Influence of Different Elastic Moduli of Dowel and Core on Stress Distribution in Root
}

\author{
Shinichi UKON, Hiroko MOROI ${ }^{1}$, Kimie OKIMOTO ${ }^{1}$ \\ Makoto FUJITA, Masatsugu ISHIKAWA, Yoshihiro TERADA ${ }^{1}$ \\ and Hironobu SATOH \\ Department of Prosthodontics, Division of Fixed Prosthodontics \\ and Stomatognathic Physiology, Fukuoka Dental College \\ 2-15-1 Tamura, Sawara-ku, Fukuoka, 814-0193 Japan \\ ${ }^{1}$ Department of Prosthetic Dentistry I, Faculty of Dentistry, \\ Kyushu University \\ 3-1-1 Maidashi, Higashi-ku, Fukuoka, 812-8582 Japan
}

Received September 24, 1999/Accepted December 10, 1999

\begin{abstract}
This study was carried out to investigate the influences of elastic moduli of the dowel-core combination on the stress distribution in the root by the use of 2-dimensional finite element analysis. The peak stress at the dowel-cement interface was influenced strongly by a change of elastic modulus of the post (from $20,000 \mathrm{~kg} / \mathrm{mm}^{2}$ as a hard prefabricated post to $8,000 \mathrm{~kg} / \mathrm{mm}^{2}$ as a custom cast post) for both vertical and 45 degree oblique loading $(\rho>90 \%)$. Peak dentinal stress adjacent to the luting cement layer depended only on the post material for vertical loading $(\rho \doteqdot 99 \%)$. In contrast, the post and core materials (from $8,000 \mathrm{~kg} / \mathrm{mm}^{2}$ as cast core to $300 \mathrm{~kg} / \mathrm{mm}^{2}$ as composite resin core) acted in cooperation on the stress magnitude for oblique loading, but the influence of the core material was stronger than that of the post ( $\rho$ of core $\fallingdotseq 41 \%$ and $\rho$ of post $\fallingdotseq 26 \%$ ).

On the other hand, at the marginal region the effect of the core material contributed more than $86 \%$ to the peak stress value for both loadings, and the post material affected at most about $11 \%$ of the bending resistance.
\end{abstract}

Key words : Dowel-core, Finite element analysis, Stress distribution

\section{INTRODUCTION}

Placement of a dowel-core for retaining final restorations is a fundamental technique when a large amount of the coronal structure of the abutment tooth has been lost or only the root is remaining. A core provides the retention and resistance form for the restoration, and a post serves to retain the core. In addition, it is considered as a reinforcement for the endodontically-treated weakened root structure. Dowel-cores are made by various techniques such as a traditional cast core, cast-joint with prefabricated dowel-post, or buildup plastic filling materials combined with a prefabricated post $^{1,2}$. Especially popular today is the use of composite resin core with prefabricated dowel post, principally because of the clinical merits, i.e. simplified clinical procedures, reduction of the time cost due to the very short polymerization time, developments in bonding systems to dentin ${ }^{3)}$, involving inverted undercuts, and improved commercial dowel system kits. 
However there is a possibility that an increased incidence of vertical root fracture which can not be seen in the vital tooth has a strong relation to the dowel placement. The functional force applied to the final restoration transmitted from the dowel post via the core creates significant stress within the supporting root structure. It is possible that the retention mechanisms of the cemented posts in dowel spaces are the same, except for the self-threaded type, even if the core materials are different. However Kovarick et al. reported that the resin core had less durability and failed more frequently than the amalgam core in their fatigue test $\mathrm{t}^{4)}$. On the other hand, Hatzikyriakos et al. showed that there was no significance between different restorative techniques during a three year clinical observation ${ }^{5)}$.

In terms of the mechanical properties, the strengths and elastic moduli of the dowel-core are also important. The elastic modulus is related to deflection and deformation, and to the rigidity of a post within a limited size. Moreover, water sorption by composite resins in the long term has a tendency to decrease their strength and elastic modulus. Comparisons of dowel post designs were investigated by various in vitro studies such as photoelastic experiments or the finite element method analysis and fracture resistance test ${ }^{6-10)}$. However, few studies have reported the effects of the material properties of the dowel and core on the stress concentration in the root. Are the elastic moduli of both the dowel and core, as well as the post design, important factors responsible for differences in stress distribution within the root dentin?

The purpose of this study was to compare 1) the mechanisms of different response in stress transfer to the root by means of the alterations of elastic moduli of core and dowel post, and 2) which variables have the greatest influence on the root stress distribution, by the use of a two dimensional finite element method.

\section{MATERIALS AND METHODS}

To evaluate the roles of the dowel post and core, the parameters of elastic moduli of both were set to analyze the individual effects and their contributions to the stress distribution in the radicular portion. Elastic moduli and Poissons' ratios of the dowel-core materials and components of dental structures used for finite element method (FEM) analysis are presented in Table $1^{11-19)}$, that is, the elastic moduli of the dowel posts were set at three values, $20,000 \mathrm{~kg} / \mathrm{mm}^{2}, 15,000 \mathrm{~kg} / \mathrm{mm}^{2}$ and $8,000 \mathrm{~kg} / \mathrm{mm}^{2}$, representing hard prefabricated dowel posts (like stainless steel and cobaltchromium), medium hard prefabricated dowel posts (like nickel-chromium and titanium alloy) and custom cast dowel (cast gold and silver alloys).

In spite of a literature survey, direct information concerning the decrease in elastic modulus of composite resins immersed in water for very long periods could not be obtained. It was estimated from two previous reports (immersion of composite resins in water for a three year period ${ }^{20)}$, and core composite resins stored in water for 12 weeks ${ }^{21)}$ ) that the elastic modulus reached about $500 \mathrm{~kg} / \mathrm{mm}^{2}$ after 3 years and 340 $400 \mathrm{~kg} / \mathrm{mm}^{2}$ after five years. Considering this result, the elastic moduli of cores were set at both $300 \mathrm{~kg} / \mathrm{mm}^{2}$ and $600 \mathrm{~kg} / \mathrm{mm}^{2}$ for composite resins, and $8,000 \mathrm{~kg} / \mathrm{mm}^{2}$ for 
the cast core.

A dowel-core was designed on the following assumption. The greater part of the coronal tooth structure was destroyed over the cement-enamel junction, having only the root. The core was designed so that the occlusal surface was removed by $1.5 \mathrm{~mm}$

Table 1 Material properties of reconstructed tooth with dowel-core and metal crown. Components are corresponding to the parts in Fig.1.

\begin{tabular}{lcccc}
\hline \multicolumn{1}{c}{ Material } & Component & $\mathrm{E}\left(\mathrm{kg} / \mathrm{mm}^{2}\right)$ & $v$ & Reference \\
\hline Cast crown & (A) & 8,000 & 0.33 & 14 \\
Core & (B) & & & \\
$\quad$ Composite resin & & 300 & 0.30 & $*$ \\
& & 600 & 0.30 & $*$ \\
Cast alloy & & 8,000 & 0.33 & 14,15 \\
Dowel post & (C) & 20,000 & 0.30 & 11,12 \\
& & 15,000 & 0.30 & 13 \\
Dental cement & & 8,000 & 0.30 & 14,15 \\
Dentin & (D) & 1,300 & 0.30 & 16 \\
Periodontal ligament & (E) & 1,500 & 0.35 & 17 \\
Alveolar bone & (F) & 1 & 0.45 & $*$ \\
$\quad$ Cortical & (G) & & & \\
$\quad$ Cancellous & & 1,500 & 0.30 & 18 \\
\hline
\end{tabular}

*: estimation

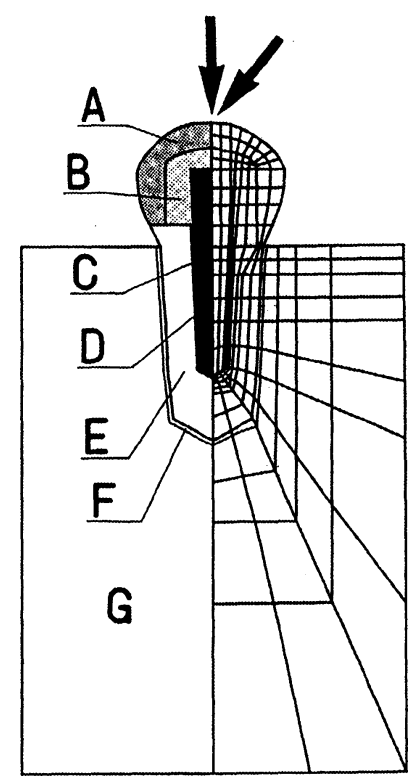

Fig. 1 Cross sectional tooth model of the lower secondary premolar restored with dowel-core and crown under two loading direction. 
reduction, and the coronal proximal wall taper was 6 degrees. The dowel post with a six degree taper was one-third the diameter and two-thirds the length of the root. The dowel post was cemented with a $100 \mu \mathrm{m}$ layer of zinc phosphate cement. A slight thickness full shoulder margin was prepared at the same level as the core margin without bracing the cervical tooth structure by the crown margin, in order to remove the ferrule effect and provide a severe condition to the dowel-core ${ }^{22}$. A two dimensional FEM model of the lower premolar restored with dowel-core and full cast crown was constructed in mesio-distal cross section with $1 \mathrm{~mm}$ thickness according to the anatomical morphology of Fujita et al. ${ }^{23)}$ In addition, some modification was done to maintain geometric symmetry and to avoid sharp corners. Identical shaped cores were prepared by cast, cast-joint, or core composite resin buildup techniques (at two elastic moduli), then they were added to dowels with three different elastic moduli. Cores were placed directly onto the dentinal structure without luting cement. The model was divided into 336 quadrant elements with eight nodes. All adjacent elements were connected rigidly. A $60 \mathrm{~g}$ static force, considered to be the elastic limit of the periodontal ligament, was applied at the cusp tip along the tooth axis vertically and at an angle of 45 degrees, as shown in Fig. 1. For comparing stress concentrations, the control model in which the dowel-core components were replaced by all dentin and all composite resin were also analyzed. A total of twenty-two models were analyzed (Table 2). To evaluate the amount of stress, von Mises' equivalent stress was calculated under a linear plane strain equation by the use of a finite element analysis program (Mark, MARK Analysis Research Corp. Palo Alto, Ca, USA). The stress distribution was analyzed at the dowel-cement and core-dentin interface, and at the nearest nodes of the dentin layer adjacent to the luting cement along the dowel.

Contributing rates were calculated to estimate which of both post and core had the greater influence on stress distribution in the root by the use of a non-repeated two-way ANOVA. The independent variables were the elastic moduli of the dowelpost $\left(20,000 \mathrm{~kg} / \mathrm{mm}^{2}, 15,000 \mathrm{~kg} / \mathrm{mm}^{2}\right.$ and $\left.8,000 \mathrm{~kg} / \mathrm{mm}^{2}\right)$ and the core materials $(8,000$

Table 2 Assumptions of the dowel-core combination for FEM models

\begin{tabular}{|c|c|c|}
\hline Model & Dowel material & Core material \\
\hline $\begin{array}{l}1 \\
2 \\
3\end{array}$ & $\begin{array}{l}\text { Hard prefabricated } \\
\text { dowel }\end{array}$ & $\begin{array}{l}\text { Composite resin }\left(E=300 \mathrm{~kg} / \mathrm{mm}^{2}\right) \\
\text { Composite resin }\left(E=600 \mathrm{~kg} / \mathrm{mm}^{2}\right) \\
\text { Cast alloy (cast joint) }\end{array}$ \\
\hline $\begin{array}{l}4 \\
5 \\
6\end{array}$ & $\begin{array}{l}\text { Medium hard } \\
\text { prefabricated } \\
\text { dowel }\end{array}$ & $\begin{array}{l}\text { Composite resin }\left(\mathrm{E}=300 \mathrm{~kg} / \mathrm{mm}^{2}\right) \\
\text { Composite resin }\left(\mathrm{E}=600 \mathrm{~kg} / \mathrm{mm}^{2}\right) \\
\text { Cast alloy (cast joint) }\end{array}$ \\
\hline $\begin{array}{l}7 \\
8 \\
9\end{array}$ & Cast alloy & $\begin{array}{l}\text { Composite resin }\left(E=300 \mathrm{~kg} / \mathrm{mm}^{2}\right) \\
\text { Composite resin }\left(E=600 \mathrm{~kg} / \mathrm{mm}^{2}\right) \\
\text { Cast alloy }\end{array}$ \\
\hline $\begin{array}{c}\text { Control } \\
10 \\
11\end{array}$ & $\begin{array}{l}\text { Composite resin } \\
\text { Dentin }\end{array}$ & $\begin{array}{l}\text { Composite resin }\left(E=300 \mathrm{~kg} / \mathrm{mm}^{2}\right) \\
\text { Dentin }\end{array}$ \\
\hline
\end{tabular}


$\mathrm{kg} / \mathrm{mm}^{2}, 600 \mathrm{~kg} / \mathrm{mm}^{2}$ and $300 \mathrm{~kg} / \mathrm{mm}^{2}$ ), and the dependent variables were the peak stresses along the dowel post and core. The contributing rate $(\rho)$ was confirmed as follow;

$$
\rho(\%)=\left(\left(\mathrm{SS}_{\text {Factor }}-\mathrm{df}_{\text {Factor }} \mathrm{V}_{\mathrm{e}}\right) / \mathrm{SS}_{\mathrm{T}}\right) \times 100
$$

$\left(\mathrm{SS}_{\mathrm{Factor}}\right.$ : sum of square, $\mathrm{df}_{\mathrm{Factor}}$ : degree of freedom, $\mathrm{V}_{\mathrm{e}}$ : variance of error, $\mathrm{SS}_{\mathrm{T}}$ : total sum of square)

\section{RESULTS}

In general, the higher the elastic modulus of dowel, the greater the stress generated within the dowel-post. Stress was transferred to the adjacent structure, especially along the dowel, in all models except the control group, and a lower elastic modulus of core also produced a greater stress distribution in the cervical region. Stress counter plots for some cases are displayed in Fig. 2.

\section{Vertical loading}

The von Mises' equivalent stress at the dowel-cement/core-dentin interface, and at the dentin layer adjacent to the core and luting cement of the post for each case when load was applied vertically are plotted (Figs. 3, 5). The peak stresses ( $б$ e) for each case of dowel core combination are summarized in bar graphs (Figs. 4, 6). The stress patterns tend to be approximately similar for all models except the control models. Stress was concentrated at the end of the dowel post and near the crown margin.

\section{1) At the end of the dowel}

When a $20,000 \mathrm{~kg} / \mathrm{mm}^{2}$ elastic modulus dowel like a stainless steel prefabricated post with composite core $\left(\mathrm{E}=300 \mathrm{~kg} / \mathrm{mm}^{2}\right)$ was used, the peak stress was the highest (reached $2.3 \times 10^{-2} \mathrm{~kg} / \mathrm{mm}^{2}$ ) at the dowel-luting cement interface. When replaced by a custom cast dowel-core, the peak stress showed the lowest value $\left(1.8 \times 10^{-2} \mathrm{~kg} / \mathrm{mm}^{2}\right)$, representing a $22 \%$ decrease compared with a hard prefabricated dowel post with a resin core. In the case where the post materials were the same and the core was changed from a cast core $\left(E=8,000 \mathrm{~kg} / \mathrm{mm}^{2}\right)$ to a composite resin $\left(E=300 \mathrm{~kg} / \mathrm{mm}^{2}\right)$, the peak stress was basically unchanged. However, when the core was the same and the elastic modulus of the post varied from $20,000 \mathrm{~kg} / \mathrm{mm}^{2}$ to $8,000 \mathrm{~kg} / \mathrm{mm}^{2}$, the peak stress decreased on average for each case ( $5 \%$ slightly reduced at $\mathrm{E}=15,000 \mathrm{~kg} / \mathrm{mm}^{2}$, $20 \%$ decrease at $\left.\mathrm{E}=8,000 \mathrm{~kg} / \mathrm{mm}^{2}\right)$. The contributing rate $(\rho)$ of the post was $91.9 \%$, but the core materials did not affect intensity of the peak stress.

In the dentin layer near the post apex, the pattern of stress distribution was similar to that at the dowel-cement interface, although the magnitude of the peak stress was decreased by about $40 \%$ on average for the dowel-cement interface in each model (Figs. 5, 6). When the core was made of the same material, the highest stress $\left(\sigma \mathrm{e}=1.33 \times 10^{-2} \mathrm{~kg} / \mathrm{mm}^{2}\right.$ ) was transferred via the hard prefabricated dowel post, $\mathrm{E}=20,000 \mathrm{~kg} / \mathrm{mm}^{2}$. The dentin stress distribution was almost the same when a 


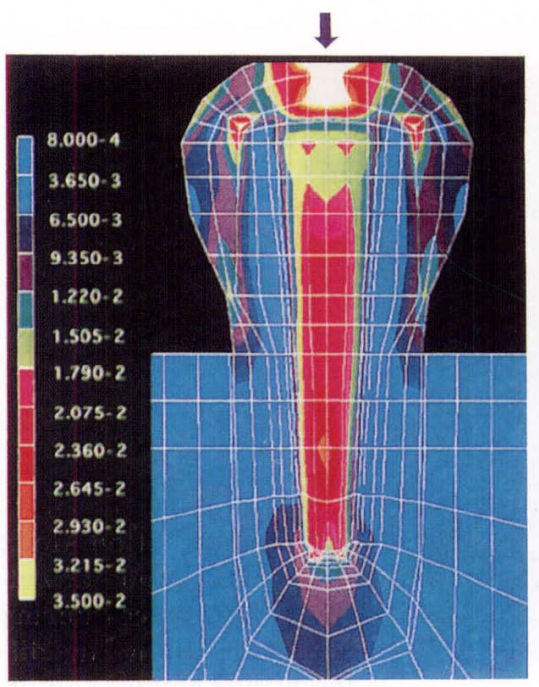

(a)

\section{Stainless steel dowel with composite resin core}

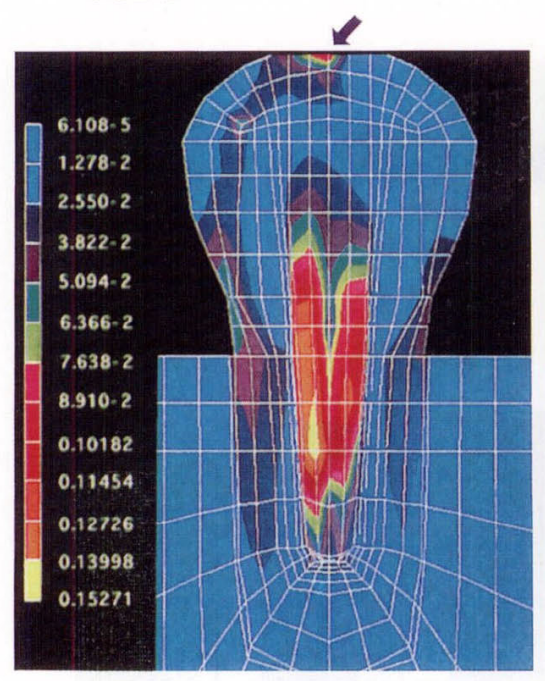

(d)

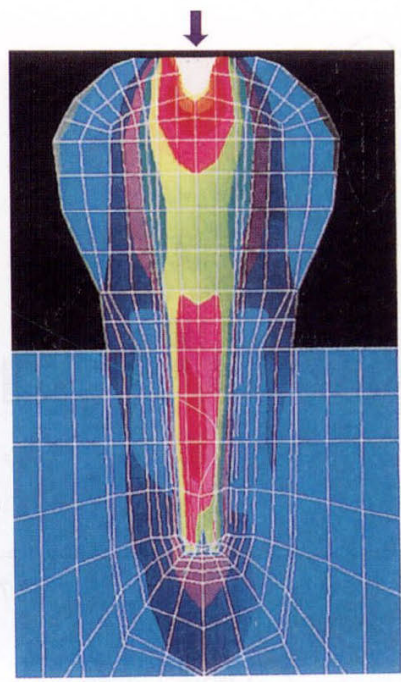

(b)
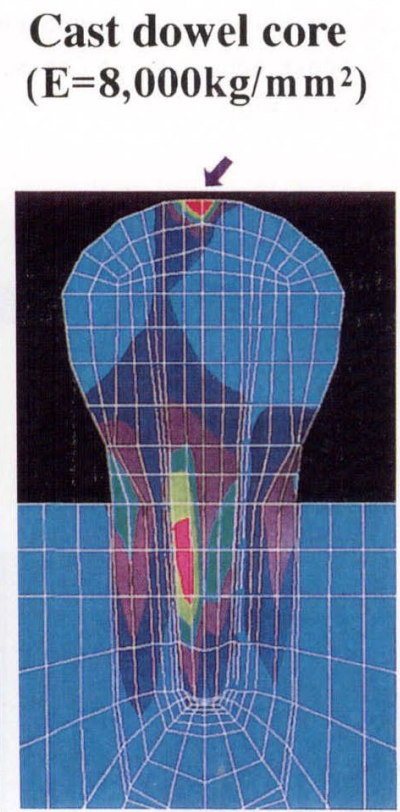

(e)

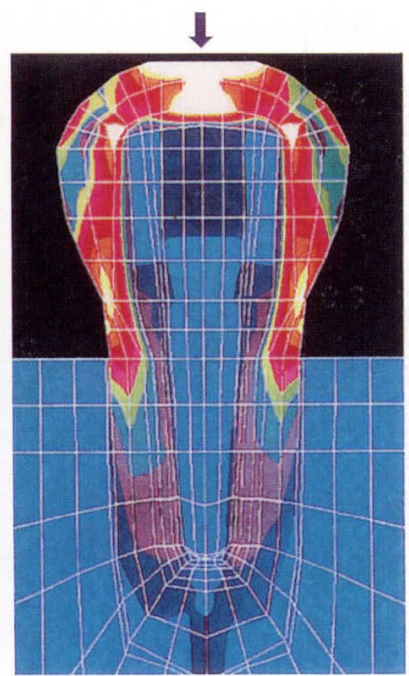

(c) All composite resin dowel core $\left(\mathrm{E}=300 \mathrm{~kg} / \mathrm{m} \mathrm{m}^{2}\right)$

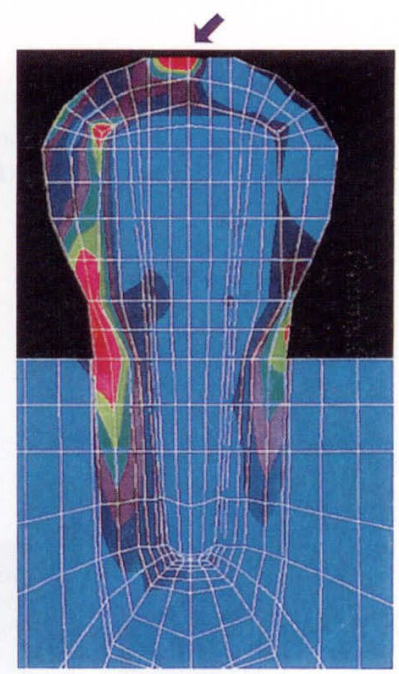

(f)

Fig. 2 Stress contour plots (von Mises' equivalent stress in $\mathrm{kg} / \mathrm{mm}^{2}$ ) for vertical loading ( $\mathrm{a}, \mathrm{b}$, c) and oblique loading (d, e, f).

Models of (a) and (d) were restored with stainless steel dowel and composite resin core, (b) and (e) models were with cast dowel-core, (c) and (f) with composite resin dowelcore as control. Note wedge-effect can be seen in dentin at the end of the dowel and stress in restoration predicts higher with composite resin core. In addition, color mappings show different intensities for vertical and oblique loading. 


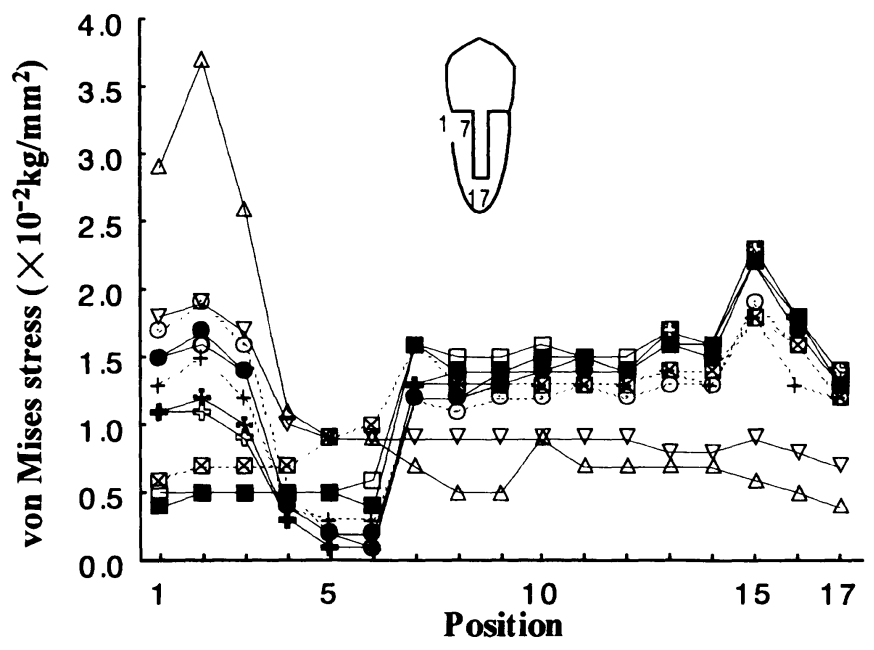

Elastic modulus $\left(\mathrm{kg} / \mathrm{mm}^{2}\right)$ of post + core

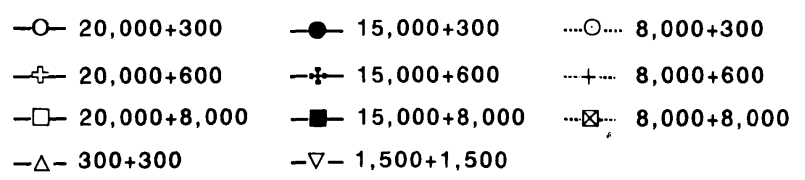

Fig. 3 Stress distribution along core-dentin and dowelcement interfaces during vertical loading in different dowel-core combinations.

The numbers on the transverse axis are positions from crown margin to post apex.

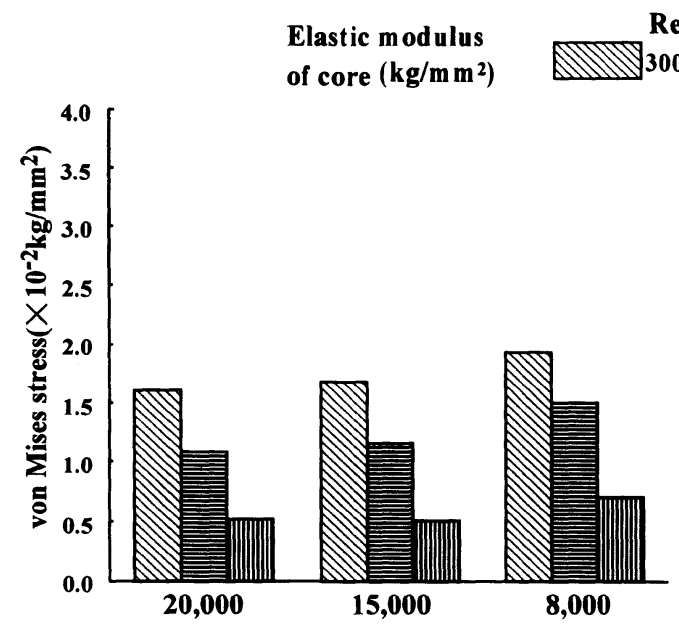

Elastic modulus of post $\left(\mathrm{kg} / \mathrm{m} \mathrm{m}^{2}\right)$

\section{Cervical portion}

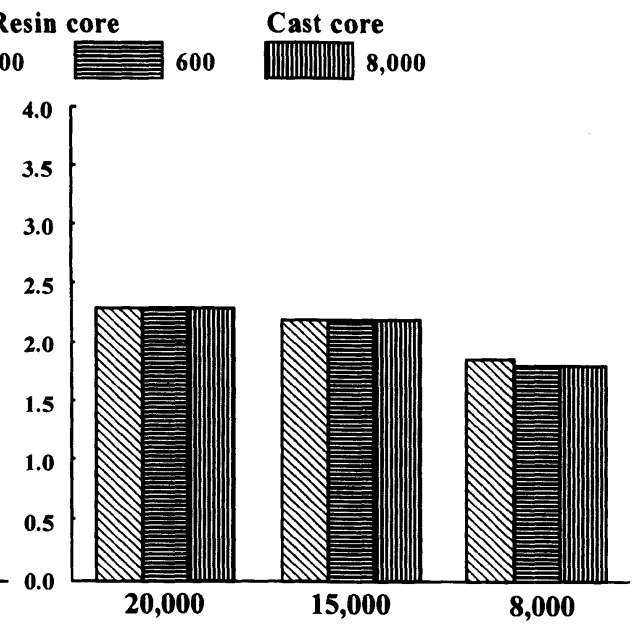

Elastic modulus of post $\left(\mathrm{kg} / \mathrm{m} \mathrm{m}^{2}\right)$

Fig. 4 The peak stress along core-dentin interface in cervical region underside of core and dowel-cement interface in radicular portion under vertical loading in different dowel-core combinations. 


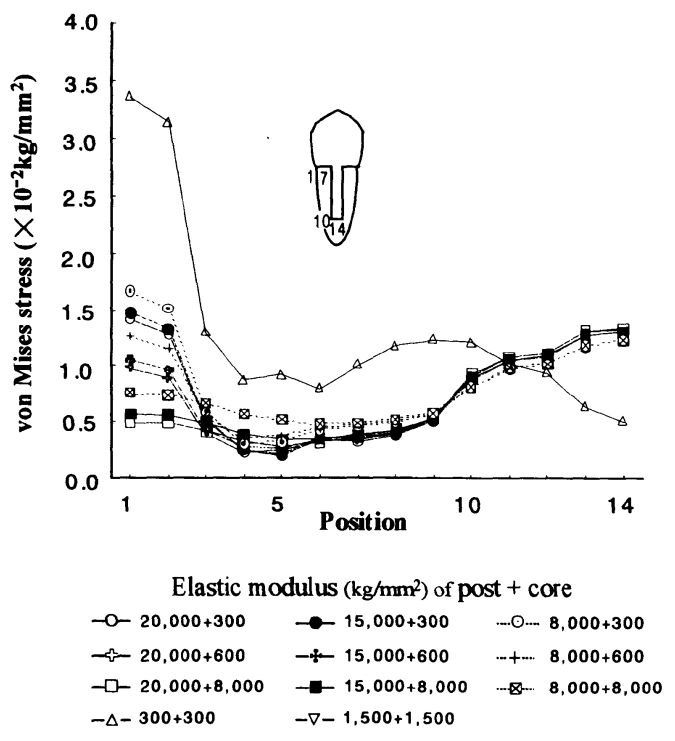

Fig. 5 Stress distribution in dentin layer along core and dowel at vertical loading in different dowel-core combinations.

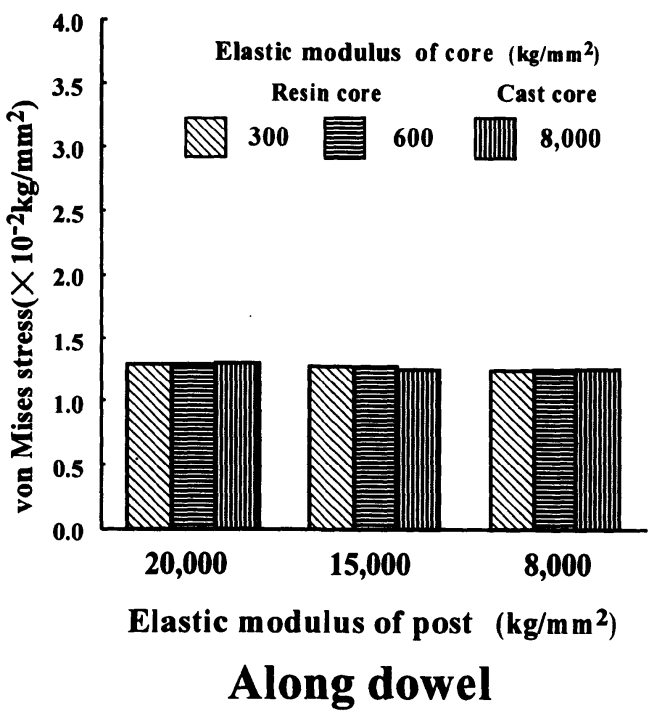

Fig. 6 The peak stress in dentin along the dowel under vertical loading in different dowel-core combinations.

medium hard dowel post, $\mathrm{E}=15,000 \mathrm{~kg} / \mathrm{mm}^{2}$, was used, while a slight reduction (no more than $8 \%$ ) was observed with the custom cast dowel-core. Only the elastic modulus of the post had an influence $(\rho=98.9 \%)$, and the core materials had no effect.

\section{2 ) At cervical portion}

On the other hand, the pattern of stress distribution at the core-dentin interface in the cervical region was different from the radicular portion (Figs. 3, 4). The peak stress was greater when the elastic moduli of the core and dowel decreased. The peak stress using a hard prefabricated dowel with a cast joint core showed the smallest value $\left(0.5 \times 10^{-2} \mathrm{~kg} / \mathrm{mm}^{2}\right)$ and the cast dowel post with a resin core $\left(\mathrm{E}=300 \mathrm{~kg} / \mathrm{mm}^{2}\right)$ showed the largest, 3.8 times as high as the hard prefabricated dowel and cast joint core combination. When the core materials were the same and the elastic modulus of post changed from $\mathrm{E}=20,000 \mathrm{~kg} / \mathrm{mm}^{2}$ to $\mathrm{E}=15,000 \mathrm{~kg} / \mathrm{mm}^{2}$, the peak stress increased slightly ( $6 \%$ greater on average). Moreover, the elastic modulus of the post reduced at $\mathrm{E}=8,000 \mathrm{~kg} / \mathrm{mm}^{2}$, the peak stress was increased by $32 \%$ on average compared with the hard prefabricated dowel. In addition, when the post material was the same and the core was changed from a cast core to a composite resin core at $\mathrm{E}=600 \mathrm{~kg} / \mathrm{mm}^{2}$, or $\mathrm{E}=300 \mathrm{~kg} / \mathrm{mm}^{2}$, the peak stress increased 2.4 times and 3.1 times, respectively.

At the cervical region near the crown margin, both the core and the dowel materials acted in cooperation to alter the stress distribution. However, $\rho$ of the core was $92.1 \%$ and that of the post was only $6.5 \%$. 


\section{45 degree oblique loading}

The load was applied on the cusp tip in an oblique direction, and the stress distribution along the dowel-cement/core-dentin interface and in the dentin layer were plotted (Figs. 7, 9) and peak stress was recorded (Figs. 8, 10). The stress concentration was located near the cervical portion and midroot of the dowel. The intensities of the peak stresses of both areas with the same dowel-core combination were about 5.4 times larger than those under vertical loading, because of bending.

\section{1 ) Along the dowel post}

The highest stress $\left(\sigma \mathrm{e}=13.3 \times 10^{-2} \mathrm{~kg} / \mathrm{mm}^{2}\right.$ ) were distributed at the mid root when a hard prefabricated dowel post with a composite resin core $\left(\mathrm{E}=300 \mathrm{~kg} / \mathrm{mm}^{2}\right)$ was used. When this was replaced by a custom cast dowel-core, the peak stress was the smallest $\left(\sigma \mathrm{e}=7.7 \times 10^{-2} \mathrm{~kg} / \mathrm{mm}^{2}\right.$ ), reduced by $42 \%$. When the dowel material was the same and the core was increased from $\mathrm{E}=300 \mathrm{~kg} / \mathrm{mm}^{2}$ to $8,000 \mathrm{~kg} / \mathrm{mm}^{2}$, the peak stresses reduced by no more than $5 \%$. When the elastic moduli of the post was decreased with the same core material, i.e. a hard prefabricated post was changed to a medium hard prefabricated dowel or cast dowel, the peak stress changed a certain degree (reduced by $13 \%$ and $38 \%$ on average for each case). The elastic modulus of dowel post contributed strongly to the stress value $(\rho=98.4 \%)$, while the core material did not.

In the root dentin adjacent to the cement layer, the inner stress was distributed uniformly along the post and concentrated near the access opening. The magnitude of the peak stress along the post for each case was decreased by about $75 \%$ on aver-

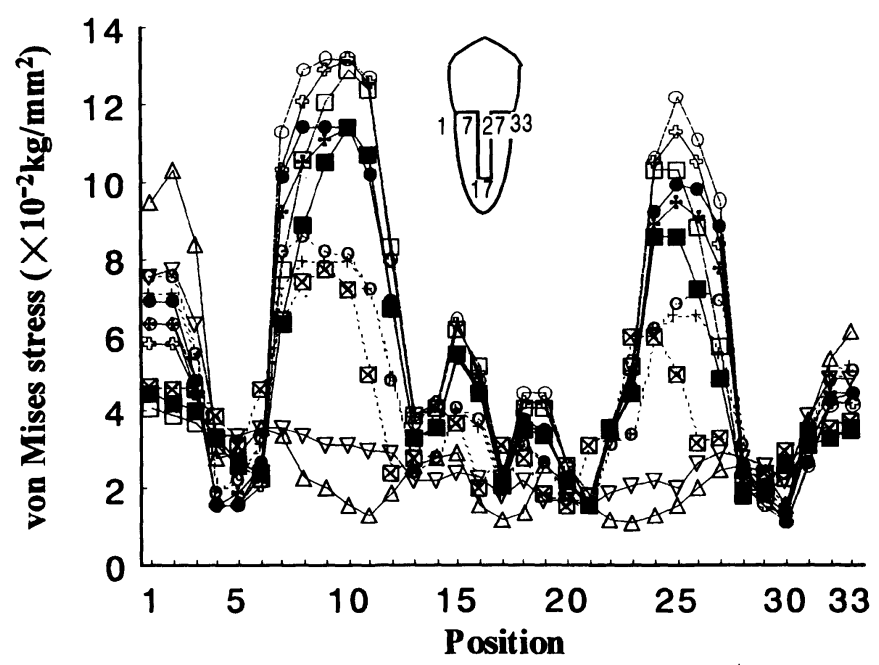

Elastic modulus $\left(\mathrm{kg} / \mathrm{mm}^{2}\right)$ of post + core

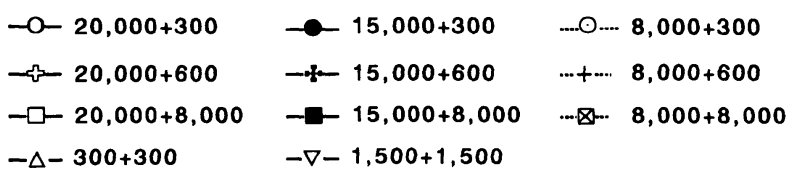

Fig. 7 Stress distribution along core-dentin interface and dowel-cement interface under oblique loading in different dowel-core combinations. 


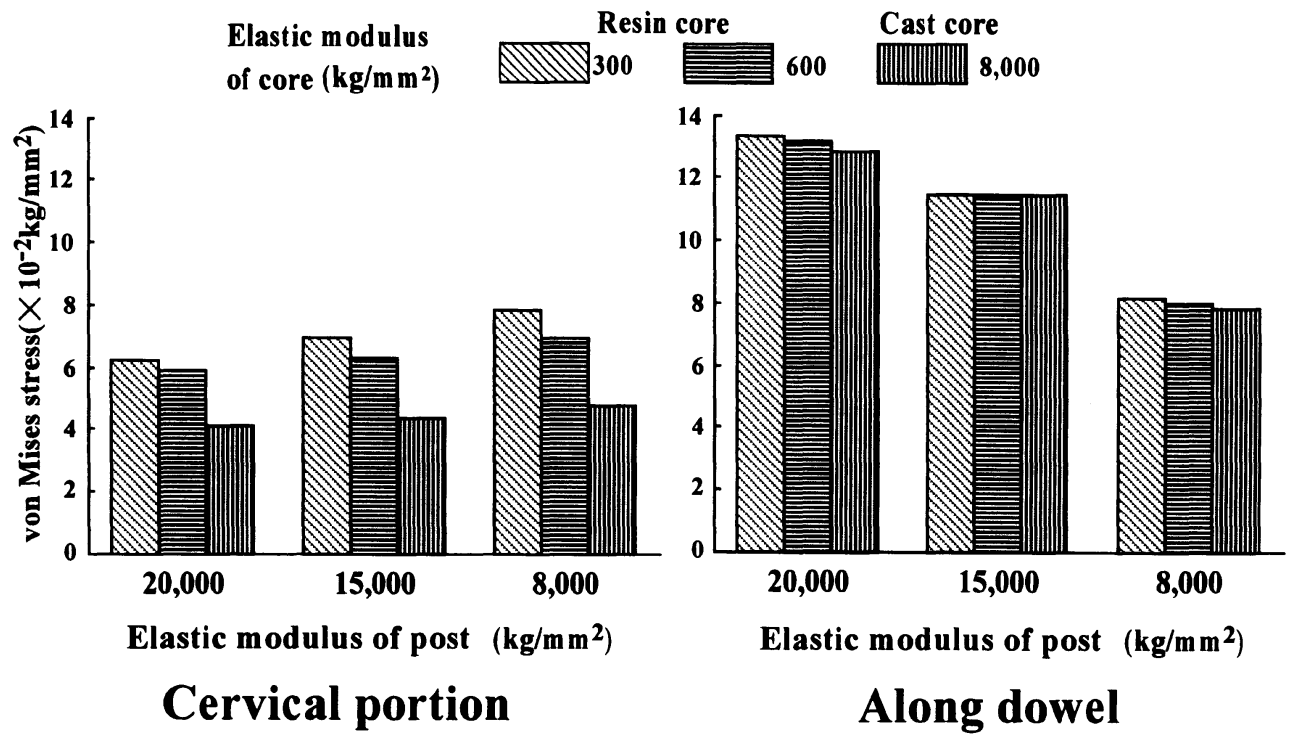

Fig. 8 The peak stress along dowel-cement interface in radicular portion under oblique loading in different dowel-core combinations.

age compared with the dowel-cement interface, but about three times as great as for vertical loading (Figs.9, 10). The maximum bending stress was produced at the crest of alveolar bone as fulcrum transferred from the cervical surface to the inner side, and this had a greater effect on the internal stress distribution rather than propagation from the dowel post. The greatest peak stress was seen with a composite resin core $\left(\mathrm{E}=300 \mathrm{~kg} / \mathrm{mm}^{2}\right)$ and cast dowel $\left(\sigma \mathrm{e}=4.2 \times 10^{-2} \mathrm{~kg} / \mathrm{mm}^{2}\right)$ and the least in a castjoint core with a hard prefabricated dowel $\left(\sigma \mathrm{e}=3.0 \times 10^{-2} \mathrm{~kg} / \mathrm{mm}^{2}\right.$ ). As the post was kept the same and elastic modulus of the core was increased, the peak stress decreased $\left(14 \%\right.$ reduced at $600 \mathrm{~kg} / \mathrm{mm}^{2}$ and $18 \%$ reduced at $8,000 \mathrm{~kg} / \mathrm{mm}^{2}$ compared with $300 \mathrm{~kg} / \mathrm{mm}^{2}$ composite resin, on average). In contrast, when a core was fabricated with the same material and the elastic modulus of the dowel was decreased, the peak stress seemed to increase $0.3 \%$ increase when a hard prefabricated post was replaced by a medium hard prefabricated dowel, and $9 \%$ increase when replaced by cast dowel). This phenomenon was very clear in a composite resin core $\left(\mathrm{E}=300 \mathrm{~kg} / \mathrm{mm}^{2}\right)$.

The elastic moduli of the dowel post and core did not greatly affect the stress distribution in the dentin along the post ( $\rho$ of post $=26.5 \%$ and $\rho$ of core $=40.8 \%$ ).

\section{2 ) Cervical portion}

The magnitude of the stress at core-dentin interface was affected greatly, about 2.8 times as much as the dowel region, on average, for each case. The stress increased substantially as the elastic moduli of both core and dowel were reduced. The highest stress was seen in the case of a resin core with a cast dowel $\left(\sigma \mathrm{e}=7.5 \times 10^{-2} \mathrm{~kg} / \mathrm{mm}^{2}\right)$ and the lowest was the cast-joint core with stainless dowel combination $(\sigma e=4.1 \times$ 


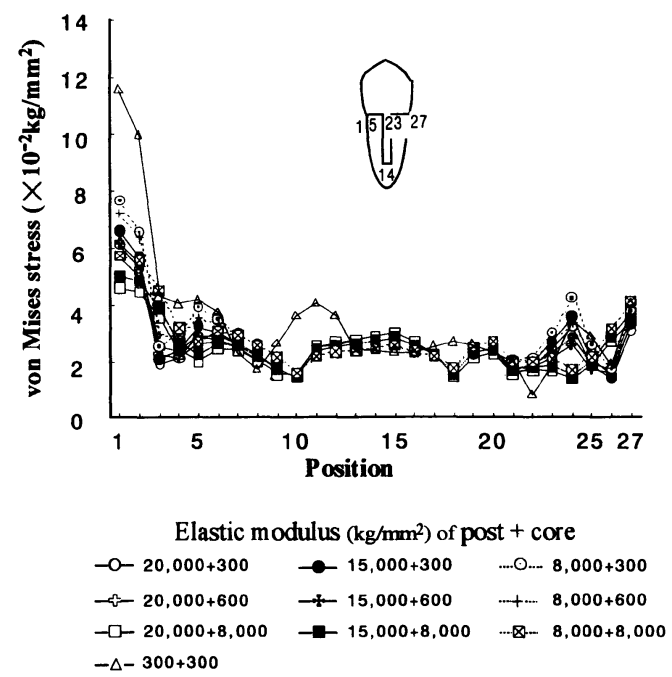

Fig. 9 Stress distribution in dentin layer along core and dowel under oblique loading in different dowel-core combinations.

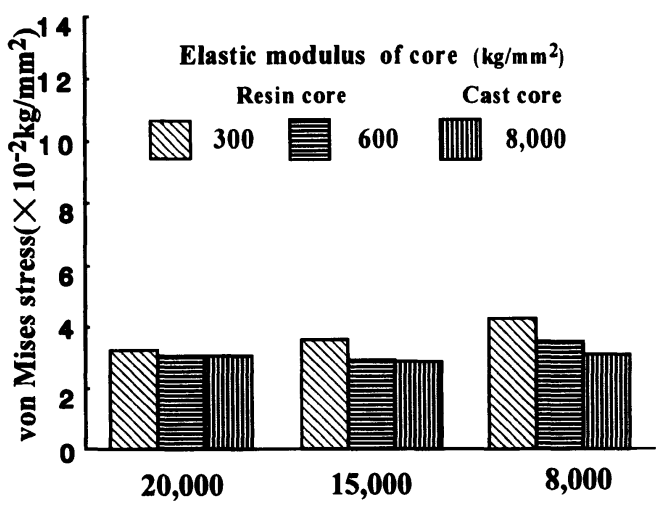

Elastic modulus of post $\left(\mathrm{kg} / \mathrm{m} \mathrm{m}^{2}\right)$

\section{Along dowel}

Fig. 10 The peak stress in dentin layer along dowel under oblique loading in different dowel-core combinations.

$\left.10^{-2} \mathrm{~kg} / \mathrm{mm}^{2}\right)$. Alteration of the dowel post material produced a certain change (18\% increased when the dowel was reduced from $\mathrm{E}=20,000 \mathrm{~kg} / \mathrm{mm}^{2}$ to $\mathrm{E}=8,000 \mathrm{~kg} / \mathrm{mm}^{2}$ ), however, a $60 \%$ was seen on average when the elastic modulus of the core was reduced from $\mathrm{E}=8,000 \mathrm{~kg} / \mathrm{mm}^{2}$ to $\mathrm{E}=300 \mathrm{~kg} / \mathrm{mm}^{2}$. It was certain that both posts and cores cooperated in resistance to bending. However, the core material contributed more intensively $(\rho=86.4 \%)$ than the dowel $(\rho=10.8 \%)$ to the stress concentration in the cervical portion.

\section{DISCUSSION}

Failure characteristics of the dowel-core technique are differentiated into three categories: 1) dislodgment by loss of retention, which can be re-cemented, 2) rerestoration involving fabrication of a new post and core or with minor horizontal fracture, and 3) vertical root fracture. The incidence of vertical root fracture is low, however, it is considered as absolute failure because the result is extraction. The wedge effect from placement of the dowel post has been suspected to be the cause of vertical root fracture, from observations of fractured root shape and stress concentration of the post design.

In clinical evaluations of the dowel-core under epidemiological survey, Mentink et $a l{ }^{24)}$ and Bergman et $a{ }^{25)}$ also reported that the failure rate with the dowel-core was less than $3 \%$ per year. Sorensen stated that a tapered cast dowel-core influenced the vertical root fracture more significantly than a prefabricated parallel side post and amalgam or composite resin core ${ }^{26)}$. Hatzikyriakos et al. suggested that there was no 
Table 3 Contributing rate of elastic moduli of post and core to peak stresses in root

$(\%)$

\begin{tabular}{|c|c|c|c|c|c|c|}
\hline \multirow[b]{3}{*}{ Factor } & \multicolumn{3}{|c|}{ Vertical loading } & \multicolumn{3}{|c|}{ Oblique loading } \\
\hline & \multicolumn{2}{|c|}{ Along post } & \multirow{2}{*}{$\begin{array}{l}\text { Cervical } \\
\text { (interface) }\end{array}$} & \multicolumn{2}{|c|}{ Along post } & \multirow{2}{*}{$\begin{array}{c}\text { Cervical } \\
\text { (interface) }\end{array}$} \\
\hline & Interface & Dentin & & Interface & Dentin & \\
\hline post & 91.9 & 98.9 & 6.5 & 98.4 & 26.5 & 10.8 \\
\hline core & - & - & 92.1 & - & 40.8 & 86.4 \\
\hline
\end{tabular}

significant difference between the parapost with the composite resin core and an amalgam core $^{5)}$. In vitro studies have led to a disagreement about the durability of composite resin versus amalgam as core materials, from the result of fatigue tests $^{4,27)}$. The materials of post/core combination might not reach agreement between clinical researches and in vitro studies.

Regarding the influence of the dowel and core materials on stress distribution, Yaman et al. reported that the effects of different core materials- composite resin, amalgam and cast core- did not cause significant alteration of the stress concentration around the post by photoelastic experiments, and also found that as the physical properties of the core increased, the stress became concentrated greatly at the region of cervical third of the post ${ }^{28)}$. This is in disagreement with the present study, in which the stress concentration in the root tended to be significantly different; higher stress was distributed when the elastic moduli of core decreased and that of dowel increased. Each model experiment might have some limitations. One of the causes of this difference seems to be that the photoelastic experimental method has difficulty in coordinating the elastic moduli of complex materials. Although FEM analysis also include errors by properties character, meshing, boundary condition, it is easier to coordinate the material properties.

This study suggested that a dowel post with a higher elastic modulus has more stress gathering capacity, which propagates to an adjacent structure such as the luting cement or root dentin. As dentinal stresses under the core were considered to be almost the same as those at core-dentin interface, these stresses were not compared in this study. It might be responsible for no luting cement layer under core in this FEM model. The cement layer seemed to re-distribute stress. Contributing rates to the peak stress values by the change of elastic moduli of dowel posts and cores are shown in Table 3. The change of elastic modulus of the post affected greatly the peak stress at the interface of the post during both vertical loading and oblique loading. The contributing rate of the dowel post was more than $90 \%$, and the core material did not contribute. Also the change of the dentin stress adjacent to a luting cement along the post during vertical loading was explained by the variation of the elastic modulus of the post, contributing rate almost $100 \%$. The wedge-effect appeared distinctly in the root dentin when vertical force was applied (Fig. 2-a, b). In contrast, the peak dentin stress along the post during oblique loading depended more 
on the core material than the post; $\rho$ of core was about $41 \%$ and $\rho$ of post was about $26 \%$. There could be an effect of the bulk of the remaining root structure resistance, because of the residual error in the same degree.

On the assumption that the mean stress value along the dowel in all dentin models (from the position 7 to 17 on transverse axis in Fig. 3 and from position 7 to 27 in Fig. 7 of control model \#11) was standard stress, it indicated $0.85 \times 10^{-2} \mathrm{~kg} / \mathrm{mm}^{2}$ during vertical loading, and $2.3 \times 10^{-2} \mathrm{~kg} / \mathrm{mm}^{2}$ during oblique loading. The factor of stress concentration was 2 to 3 at the dowel-cement interface (Fig. 3) and 1.5 at the dentinal structure (Fig. 5) by the placement of cast/prefabricated dowel during vertical loading. Moreover, it increased by 5.8 times at the interface (Fig. 7) and 1.3 to 1.8 in the dentin on oblique loading (Fig. 9).

Actually, high elastic modulus prefabricated dowels have some merits for flexural rigidity and freedom from casting defects. As a result, it is possible to reduce the post diameter and increase the bulk of the remaining root structure in clinical. Initial cracking or destruction within the cement layer might occur at first, and greater stress will be concentrated at the fracture point. However, the stress distribution in the cement layer was not analyzed in this study, because of the thin and long elements, and similarity of the material properties and character to adjacent root dentin. Compared with the all composite resin dowel-core as a control (model \#10), the post material had a great influence on the stress distribution along the post. The magnitude of the all composite resin core and post was the lowest in the dowel region, but it demonstrated the greatest stress distribution at the cervical portion, three times as great as the cast dowel-core, seven times that of the stainless steel dowel with a cast joint core, and about twice that of the all-dentin model (Figs. 3, 7). It can be seen that the stress concentration at the cervical dentin adjacent to the alveolar crest tended to decrease relatively as the elastic modulus of the dowel increased. This result might indicate that a higher elastic modulus of the post reinforces the root structure against bending.

The stress distributions at the cervical region under both loading directions were affected more strongly by the change of elastic modulus of core than by the post material ( $\rho$ of core was about $90 \%$ and $\rho$ of post was about $10 \%$ ). A decrease in elastic modulus of the core material led to a higher stress distribution in the cervical region. It caused a new problem in adhesive durability of the luting cement or composite resin. Horizontal fracture of the post or core, dislodgment of a restoration could be expected in this case ${ }^{29,30)}$. In addition, a greater stress was distributed in the restorations. This could be responsible for the higher fracture incidence of jacket crowns fabricated from brittle materials.

Clinically, to avoid vertical root fracture it might be advisory to use materials possessing a too high elastic modulus for the dowel post and a too low elastic modulus for the core material. 


\section{CONCLUSION}

This investigation was performed to clarify the effect of elastic moduli of the dowel core combination on the stress concentration within the root structure by using FEM analysis, the following conclusions were made:

1. Oblique force generated bending and caused a greater stress concentration in the root structure; about three times that of vertical force.

2 . Dentin stress was concentrated at the dowel apex by vertical force and at the access opening by oblique force.

3 . Higher modulus dowel-posts had a greater stress gathering potential, and the stress was propagated to the adjacent structure.

4. The dowel-post with a high elastic modulus had a significant wedge-effect on the root structure.

5 . The lower elastic the modulus of the core, the higher the stress distributed to the marginal region of the root and restoration, in addition to a higher stress distribution around the post.

\section{REFERENCES}

1) Shillingburg, H. T.Jr., Hobo, S., Whitesett, L. D., Jakobi, R. and Brackett, S. E.: Fundamentals of fixed prosthodontics, 3rd ed., Quintessence Co., Chicago, 1997, pp.194-206.

2) Rosenstiel, S. F., Land, M. F. and Fujimoto J.: Contemporary fixed prosthodontics, 2nd ed., Mosby Co., St.Louis, 1988, pp.238-267.

3) Swift, E.J.Jr, Perdiãgo,J., and Heymann, H. O.: Bonding to enamel and dentin: A brief history and state of art,1995, Quintessence Int. 26(2) : 95-110, 1995.

4) Kovarik, R. E., Breeding, L. C. and Caughman, W. F.: Fatigue life of three core materials under simulated chewing conditions, J Prosthet Dent 68:584-590, 1992.

5) Hatzikyriakos, A.H., Reisis, G.I. and Tsingos, N.: A 3-year postoperative clinical evaluation of posts and cores beneath existing crowns. J Prosthet Dent $67:$ 454-58, 1992.

6) Standlee, J. P., Caputo, A. A., Holcomb, J. and Trabert, K. C.: The retentive and stressdistributing properties of a threaded endodontic dowel, J Prosthet Dent $44: 398-404,1980$.

7) Assif, D., Beitenski, A., Pilo, R. and Oren, E.: Effect of post design on resistance to fracture of endodontically treated teeth with complete crowns, $J$ Prosthet Dent $69: 36-40$, 1993.

8) Ko, C. C., Chu, C.S., Chung, K. H. and Lee, M. C.: Effects of posts on dentin stress distribution in pulpless teeth, J Prosthet Dent $68: 421-427,1992$.

9) Pao, Y.C., Reinhardt, R. A. and Krejci, R. F.: Root stresses with tapered-end post design in periodontally compromised teeth, J Prosthet Dent $57: 281-286,1987$.

10) Holmes, D. C., Diaz-Arnold, A. M. and Leary, J. M.: Influence of post dimension on stress distribution in dentin, $J$ Prosthet Dent $75: 140-147,1996$.

11) Anderson, J. H.: Applied dental materials, 3rd ed., Blackwell Scientific Publications, Oxford, 1967, pp105.

12) Anderson, J. H.: Applied dental materials, 3rd ed., Blackwell Scientific Publications, Oxford, 1967, pp92.

13) Togaya, T., Suzuki, M., Tsutsumi, S. and Ida, K.: An application of pure titanium to the metal porcelain system, Dent Mat $J$ 2:210-219, 1983.

14) Anderson, J. H.: Applied dental materials, 3rd ed., Blackwell Scientific Publications, Oxford, 1967, pp77-80

15) Miyazaki,T., Nishimura, F. and Nomoto, N.: Measurement of yield strength of dental 
materials by compressive test. 2nd report about silver alloy, $J J$ Dent Mater 3:333-337, 1984. (in Japanese)

16) Craig, R. G., Peyton, F. A. and Johnson, D. W.: Compressive properties of enamel, dental cements, and gold. J Dent Res 40 : 936-945, 1961.

17) Anderson, J. H.: Applied dental materials, 3rd ed., Blackwell Scientific Publications, Oxford, 1967, pp296.

18) Carter, D. R., Spengler, D. M.: Mechanical properties and composition of cortical bone, Clin Orthop Rel Res $135:$ 192-217, 1978.

19) Knoell, A. C.: A mathematical model of a in vivo human mandible, $J$ Biomech $10: 159$ $166,1977$.

20) Matukawa, I. and Arai, K.: A study on posterior composite resins-The influence of long-term water immersion on physical and mechanical properties-, $J J$ Dent Mater 7 : 425-438, 1988. (in Japanese)

21) Yamada, T., Hosoda, H. and Tsurugai, T.: Classification and several mechanical properties of core composite resins, $J J$ Dent Mater $9: 205-217,1990$. (in Japanese)

22) Libman, W. I. and Nicholls, J. I.: Load fatigue of teeth restored with cast post and cores and complete crowns, Inter $J$ Prosthodont 8: 155-161, 1995.

23) Fujita, T. and Kirino, T.: Anatomy of the teeth, 19th ed., Kanehara Publish Co., Tokyo, 1973, pp60-62. (in Japanese)

24) Mentink, A. G. B., Meeuwissen, R., Käyser, A. F. and Mulder, J.: Survival rate and failure characteristics of the all metal post and core restoration., $J$ Oral Rehabil 20 : 455-461, 1993.

25) Torbjörner, A., Karlsson, S. and Ödeman, P. A.: Survival rate and failure characteristics for two post designs, $J$ Prosthet Dent 73 : 439-444, 1995.

26) Sorensen, J. A. and Martinoff, J. T.: Clinically significant factors in dowel design, $J$ Prosthet Dent 52 : 28-35, 1984.

27) Cohen, B. I., Pagnillo M. K., Newman, I., Musikant, B. L. and Deutsch, A. S.: Cyclic fatigue testing of five endodontic post designs supported by four core materials, $J$ Prosthet Dent 78 : 458-464, 1997.

28) Yaman, P. and Thorsteinsson, T.S.: Effect of core materials on stress distribution of posts, J Prosthet Dent $68: 416-420,1992$.

29) Chan, R.W. and Bryant, R. W.: Post-core foundations for endodontically treated posterior teeth, J Prosthet Dent 48: 401-406, 1982.

30) Martinez-Insua, A., Silva, L. D., Rilo, B. and Santana, U.: Comparison of the fracture resistances of pulpless teeth restored with a cast post and core or carbon-fiber post with a composite core, $J$ Prosthet Dent $80: 527-532,1998$. 